\title{
Insulin sensitization with a peroxisome proliferator-activated receptor $\gamma$ agonist prevents adrenocortical lipid infiltration and secretory changes induced by a high-sucrose diet
}

\author{
Camila Martinez Calejman, Juan M Di Gruccio, María E Mercau, Esteban M Repetto, Francisco Astort, \\ Rocío Sanchez, Matías Pandolfi ${ }^{1}$, Gabriela Berg ${ }^{2}$, Laura Schreier ${ }^{2}$, Pablo Arias ${ }^{3, *}$ and Cora B Cymeryng* \\ Department of Human Biochemistry, School of Medicine, University of Buenos Aires (UBA), CEFYBO, CONICET, Paraguay 2155, Buenos Aires C1121ABG, \\ Argentina \\ ${ }^{1}$ Department of Biodiversity and Experimental Biology, School of Sciences, University of Buenos Aires (UBA), Buenos Aires, Argentina \\ ${ }^{2}$ Department of Clinical Biochemistry, School of Pharmacy and Biochemistry, INFYBIOC, University of Buenos Aires (UBA), Buenos Aires, Argentina \\ ${ }^{3}$ Department of Physiology, School of Medicine, University of Rosario, Rosario, Argentina \\ (Correspondence should be addressed to C B Cymeryng; Email: cymeryng@fmed.uba.ar) \\ *(P Arias and C B Cymeryng contributed equally to this work)
}

\begin{abstract}
It has been hypothesized that deviations in glucocorticoid secretion and/or action may contribute to somatic and biochemical changes observed in patients with and animal models of insulin resistance (IR). In this study, we analyzed changes in rat adrenocortical function and morphology associated with the development of IR, generated in male adult rats by the addition of $30 \%$ sucrose to the drinking water. Caloric intake, body and adipose tissue weights, and biochemical parameters associated with IR were determined. Expression levels of Star, Cyp11A1, Mc2r, Ppary (Pparg), and Cd36 were evaluated by real-time PCR, histochemical analysis of the adrenal cortex was performed using Masson's trichrome and Sudan III staining, and corticosterone levels were measured by RIA. After 7 weeks of sucrose administration, higher serum glucose, insulin, and triglyceride levels and an altered glycemic response to an
\end{abstract}

i.p. insulin test were detected. Adrenal glands showed a neutral lipid infiltration. An increase in Star, Cyp11A1, $M c 2 r$, Pparg and Cd36 and a decrease in $M c 2 r$ levels were also found. Furthermore, sucrose-treated animals exhibited higher basal corticosterone levels and a blunted response to ACTH injection. Noteworthy, the adrenocortical (functional and histological) abnormalities were prevented in sucrose-treated rats by the simultaneous administration of an insulin-sensitizing PPAR $\gamma$ agonist. In conclusion, sucrose-induced IR affects adrenocortical morphology and function possibly via the generation of adipokines or lipid metabolites within the adrenal gland. These abnormalities are prevented by the administration of a PPAR $\gamma$ agonist by mechanisms involving both extra- and intraadrenal effects.

Journal of Endocrinology (2012) 214, 267-276

\section{Introduction}

It has been hypothesized that deviations in glucocorticoid secretion and/or action may contribute to somatic and biochemical changes observed in patients with insulin resistance (IR)/metabolic syndrome (Bjorntorp \& Rosmond 1999, Walker 2006). Patients with chronic hypercortisolism (Cushing's syndrome) display a very similar cluster of abnormalities (Kaplan 1989, Reaven 1995) characterized by marked central obesity and insulin insensitivity, and, in rodents, a permissive role for glucocorticoids in the development of obesity and metabolic syndrome has been widely acknowledged (Shimomura et al. 1987, Dallman et al. 2004), underscoring the functional relevance of glucocorticoids in adipose pathophysiology.
Among other factors (e.g. genetic predisposition, endocrine disorders, intrauterine malnutrition, and sedentarism), diet plays a key role in the genesis of IR in humans and in laboratory animals as well. Compelling evidence indicates that excess consumption of sweet foods, particularly sugarsweetened beverages, plays an important role in the epidemic of obesity around the world (Bray et al. 2004). According to this, the administration of a fructose-enriched diet or sucroseenriched diet (SED) to laboratory animals has been successful in triggering alterations consistent with the establishment of IR (Soria et al. 2001) such as hypertension, dyslipoproteinemia, moderate hyperglycemia, and hyperinsulinemia.

In peripheral tissues, increased flux of energy fuel substrates associated with high-fat or high-sucrose diets leads to ectopic lipid accumulation, generation of reactive oxygen species 
(ROS), and cellular dysfunction, a phenomenon known as glucolipotoxicity (Krebs \& Roden 2004). Ectopic lipid accumulation has been detected in nonadipose tissues as pancreas, kidneys, blood vessels, skeletal muscle, and heart. In this sense, Zago et al. (2010) demonstrated an increase in liver weight and moderate hepatic micro- and macrovesicular steatosis in sucrose-fed animals. Although these organs can initially store some of this surplus as triglycerides, excess lipids eventually give rise to toxic lipid species that alter cellular signaling (Yang \& Barouch 2007), promote mitochondrial dysfunction (Bugger \& Abel 2008), and increase apoptosis (Unger \& Orci 2002).

It is accepted that patients displaying features of IR syndrome show a dysregulation of the hypothalamicpituitary-adrenal (HPA) axis (Bjorntorp \& Rosmond 1999, Walker 2006). Hyperactivation of the adrenal cortex could be the result of a central stimulus with higher ACTH release attributable to a state of chronic stress (Pasquali et al. 2006) or to the direct effect of humoral/hormonal mediators originated in the adipose tissue and associated with the IR state (Voutilainen 1998). In this study, we show the impact of IR, induced by a high-sucrose diet on rat adrenal morphology and function. Subsequently, we demonstrate that these alterations are prevented by treating sucrose-fed animals with an insulin-sensitizing peroxisome proliferator-activated receptor $\gamma(\operatorname{PPAR} \gamma(\mathrm{PPARG}))$ agonist (rosiglitazone).

\section{Materials and Methods}

\section{Drugs and chemicals}

ACTH was obtained from ELEA Laboratories (ACTHelea; Buenos Aires, Argentina). Moloney murine leukemia virus reverse transcriptase was from Promega. Corticosterone antiserum was kindly provided by Dr A Belanger (Laval University, QC, Canada). $\left[{ }^{1,2,6,7-3 \mathrm{H}}(\mathrm{N})\right]$ corticosterone $(0 \cdot 25 \mathrm{mCi}, 76.5 \mathrm{Ci} / \mathrm{mmol}$ ) was from PerkinElmer (Boston, MA, USA). GoTaq polymerase was acquired from Promega. The enzymatic colorimetric kits for the determination of serum glucose and triglycerides levels were from Wiener Laboratories (Rosario, Argentina). Rosiglitazone was kindly provided by Dr Rosana Felice, GlaxoSmithKline. All other chemicals were of the highest quality available.

\section{Animals and experimental procedures}

Adult male Wistar rats (200-250 g body weight) received standard chow ad libitum and either tap water (control group) or tap water with $30 \%$ of sucrose (w/v) (SED group). Animals were kept in group cages (three animals per cage) under controlled conditions $\left(23 \pm 2{ }^{\circ} \mathrm{C}\right.$, lights on $0700-1900 \mathrm{~h}$ ). Caloric intake and body weight were monitored every other day throughout the duration of the experiments.

Animals from both control and SED groups were killed 3, $5,7,9$, and 12 weeks after the initiation of the dietary intervention; animals were killed by decapitation $4 \mathrm{~h}$ after food withdrawal (between 0900 and $1000 \mathrm{~h}$ ) and blood and tissues were collected and immediately frozen.

In another set of experiments, animals were randomly assigned to four experimental groups: a) control group, b) SED group, c) control group receiving the PPAR $\gamma$ agonist rosiglitazone (group R) $4 \mathrm{mg} / \mathrm{kg}$ p.o. daily, and d) SED $+\mathrm{R}$ group, receiving sucrose and rosiglitazone simultaneously.

Blood samples were taken during morning hours between 0900 and $1000 \mathrm{~h}$. Adrenocortical function and morphology were evaluated in these animals during the seventh week of treatment. All protocols for animal treatments were evaluated and approved by the Animal Care and Use Committee (CICUAL) from the University of Buenos Aires Medical School.

\section{Intraperitoneal insulin tolerance test}

Insulin tolerance tests (ITTs) were performed after a 6 -h fast by i.p. administration of regular porcine insulin (Betalin $\mathrm{R}$, Laboratorios Beta, Buenos Aires, Argentina; 0.75 IU/kg). Blood was obtained from the tail vein after $0,15,30,45$, and $60 \mathrm{~min}$, and serum glucose levels were determined by a GOD/POD colorimetric method (Wiener Laboratories).

\section{Histological and lipid analysis of adrenal glands}

Adrenal glands were rapidly immersed for $6 \mathrm{~h}$ in $4 \%$ formaldehyde diluted in $0 \cdot 1 \mathrm{M}$ phosphate buffer $(\mathrm{pH} 7 \cdot 2)$, dehydrated, and then embedded in paraffin. Adrenals were sectioned $(5 \mu \mathrm{m})$ and stained with Masson's trichrome stain. Alternatively, adrenals were fixated in $4 \%$ formaldehyde diluted in $0.1 \mathrm{M}$ phosphate buffer $(\mathrm{pH} 7 \cdot 2)$, cryoprotected with sucrose $30 \%$ in $0 \cdot 1 \mathrm{M}$ phosphate buffer $(\mathrm{pH} 7 \cdot 2$ ), embedded in Tissue-Tek OCT (Sakura Finetek Inc., Torrance, CA, USA), and frozen at $-20{ }^{\circ} \mathrm{C}$. Cryostat sections $(10 \mu \mathrm{m})$ were cut and stained with Sudan III dye. Microscopic images were digitally captured from an Eclipse E400 microscope (Nikon, Tokyo, Japan) equipped with a photographic camera (Coolpix s10; Nikon). All images were assembled and processed in Adobe Photoshop SC (Adobe Systems) to adjust for brightness and contrast. No other adjustment was made. To measure Sudan III dye-positive stain, images were captured with a $600 \times$ achromat objective from the zona fasciculata of the adrenal gland. Images were converted to 8-bit gray scale, and a manual threshold value, first determined by visual examination, was constantly applied. Finally, images were converted to a binary form. The analysis was performed by observers masked to the protocol used in each adrenal gland. For all image processing and analysis, digitalized captured TIFF images were transferred to ImageJ Software (http://imagej.nih.gov/ij/, NIH, USA).

For the determination of triglyceride content, adrenal glands were homogenized in $50 \mathrm{mM}$ phosphate buffer, $\mathrm{pH} 7 \cdot 4$, with the addition of $100 \mathrm{mM} \mathrm{KCl}$ and phosphatase and protease inhibitors. Homogenate samples were centrifuged 
for $5 \mathrm{~min}$ at $2000 \mathrm{~g}$ and triglyceride levels were assayed in the supernatants with commercial enzymatic colorimetric kits (Wiener Laboratories).

\section{ACTH stimulation test}

Twenty-four hours before the experiments, animals were fitted under ketamine-xylazine anesthesia, with indwelling jugular cannulae (Harms \& Ojeda 1974). On the day of the experiment, the Silastic tubing was exposed and flushed with heparin-containing saline $(25 \mathrm{IU} / \mathrm{ml}) 2 \mathrm{~h}$ before the beginning of the experiment. Blood samples were obtained 0 , 15, 30, 45, and $60 \mathrm{~min}$ after ACTH injection (4 IU $/ \mathrm{kg}$ i.v.). The area under the concentration/time curve (AUC) was calculated using the trapezoid rule.

\section{RNA isolation and RT-PCR}

After killing, adrenal glands were rapidly dissected and placed on a chilled plate. After decapsulation, adrenocortical tissue was homogenized in TRIzol reagent and total RNA was obtained according to the manufacturer's instructions. RNA $(1 \mu \mathrm{g})$ was pretreated with ribonuclease-free DNase I to eliminate any possible DNA contamination and then incubated in a mixture containing $0.5 \mathrm{mM}$ dNTP mix, $25 \mathrm{ng} / \mu \mathrm{l}(8 \mu \mathrm{M})$ random primers, $1 \times$ first-strand buffer, $25 \mathrm{U}$ ribonuclease inhibitor, and $200 \mathrm{U}$ Moloney murine leukemia virus reverse transcriptase in a final volume of $25 \mu \mathrm{l}$ for $1 \mathrm{~h}$ at $42^{\circ} \mathrm{C}$. The reaction was stopped by heating at $90{ }^{\circ} \mathrm{C}$ for $5 \mathrm{~min}$. The reaction mixture was then brought to $100 \mu \mathrm{l}$ with diethylpyrocarbonate-treated water and stored at $-70{ }^{\circ} \mathrm{C}$. Reverse transcriptase was omitted in selected tubes as a control of amplification from contaminating genomic DNA.

Amplifications by real-time PCR were carried out in a Rotor-Gene 6000 Corbett Life Science Real Time Thermal Cycler (Corbett Research, Sidney, NSW, Australia) and were performed using $0.5 \mu \mathrm{l}$ cDNA in a final volume of $25 \mu \mathrm{l}$ in the following reaction mixture: $1 \times$ PCR buffer, $1.5 \mathrm{mM} \mathrm{MgCl} 2,0.2 \mathrm{mM}$ of each dNTP, $500 \mathrm{nM}$ of each specific oligonucleotide primer, 0.625 U GoTaq polymerase, and $0.96 \times$ EvaGreen.

The sequences for the oligonucleotide primers were as follows: $\beta$-actin, forward: $5^{\prime}$-CCACACCCGCCACCAGTTC- $3^{\prime}$ and reverse: 5'-GACCCATTCCCACCATCA CACC- $3^{\prime} ; \mathrm{P}_{450}$ side chain cleavage enzyme (CYP11A1), forward: 5'-GGGTGGCCTATC ACCAGTAT- ${ }^{\prime}$ and reverse: 5'-CTGAGCTACACCTTCCAGCA-3'; steroidogenesis acute regulatory protein (STAR), forward: $5^{\prime}-\mathrm{GTG}-$ GAACCCAAATGTCAAGG- $3^{\prime}$ and reverse: $5^{\prime}$-CAGCAC ACAGGTGGAACCTC-3'; melanocortin 2 receptor (MC2R), forward: 5'-GATGCTGGTTTTTATCCTGTGTC-3' and reverse: 5'-ATGC CATTGACCTGGAAGAG-3'; PPAR $\gamma$, forward: 5'-CATAAAGTCCTTCCC GCTGA-3 $3^{\prime}$ and reverse: 5'-GAAACTGGCACCCTTGAAAA- $3^{\prime}$; and fatty acid translocase (CD36), forward:
5'-CTCTGACATTTGCAGGTCCA-3' and reverse: $5^{\prime}$-CACAGGCTTTCCTTCTTTGC- $3^{\prime}$. The cycling conditions were as follows: denaturation at $95^{\circ} \mathrm{C}$ for $3 \mathrm{~min}$, 40 cycles of $20 \mathrm{~s}$ at $95^{\circ} \mathrm{C}$ and $20 \mathrm{~s}$ at $52^{\circ} \mathrm{C}$, and finally $30 \mathrm{~s}$ at $72{ }^{\circ} \mathrm{C}$. Real-time PCR results were quantified using Rotor Gene 6000 Series Software (version 1.7 Build 40, Hilden, Germany) with $\beta$-actin expression as internal control.

\section{Hormone measurements}

Corticosterone concentration in dichloromethane-extracted serum samples was determined by RIA, as described previously (Cymeryng et al. 1998). Serum insulin levels were determined using a commercial ELISA kit (Alpco Diagnostics Insulin (Rat) Ultrasensitive EIA, Salem, NH, USA).

\section{Statistical analysis}

Data were tested for normality using the KolmogorovSmirnoff test. Values are expressed as mean \pm s.E.M. Differences between groups were analyzed by unpaired $t$-test or by factorial one-way ANOVA followed by Tukey's test, as appropriate. All calculations were performed using GraphPad InStat version 3.06 for Windows (GraphPad Software, San Diego, CA, USA).

\section{Results}

Rats receiving sucrose in drinking water (SED group) and control rats (control group) were killed 3, 5, 7, 9, and 12 weeks after the initiation of the treatments. As summarized in Tables 1 and 2, caloric intake, body and adipose tissue weights, and biochemical parameters related to IR were significantly increased 7-9 weeks after the initiation of the dietary modification (SED vs control groups).

The presence of a systemic insulin-resistant state was confirmed during the seventh week of treatment by means of an ITT (Fig. 1A). Simultaneous treatment with the PPAR $\gamma$ agonist rosiglitazone normalized the results of the ITT and also prevented the increase in serum insulin, glucose, and triglyceride concentrations (Fig. 1A, B, C and D). This treatment had no effect on the increase in body and adipose tissue weights observed in animals of the SED group (Fig. 1E and F).

As an insulin-resistant state was established 7 weeks after the initiation of the dietary intervention, we chose this time point to further perform morphological and functional evaluations of the adrenal cortex of the rat in SED and in control animals, with and without rosiglitazone treatment.

Adrenal glands excised from SED-treated rats exhibited significant lower relative weights than their control counterparts. Rosiglitazone treatment did not affect this parameter

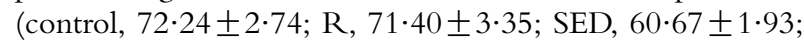
$\mathrm{SED}+\mathrm{R}, 60 \cdot 08 \pm 2 \cdot 98 \mathrm{mg} / \mathrm{kg}$ body weight, SED vs control, 


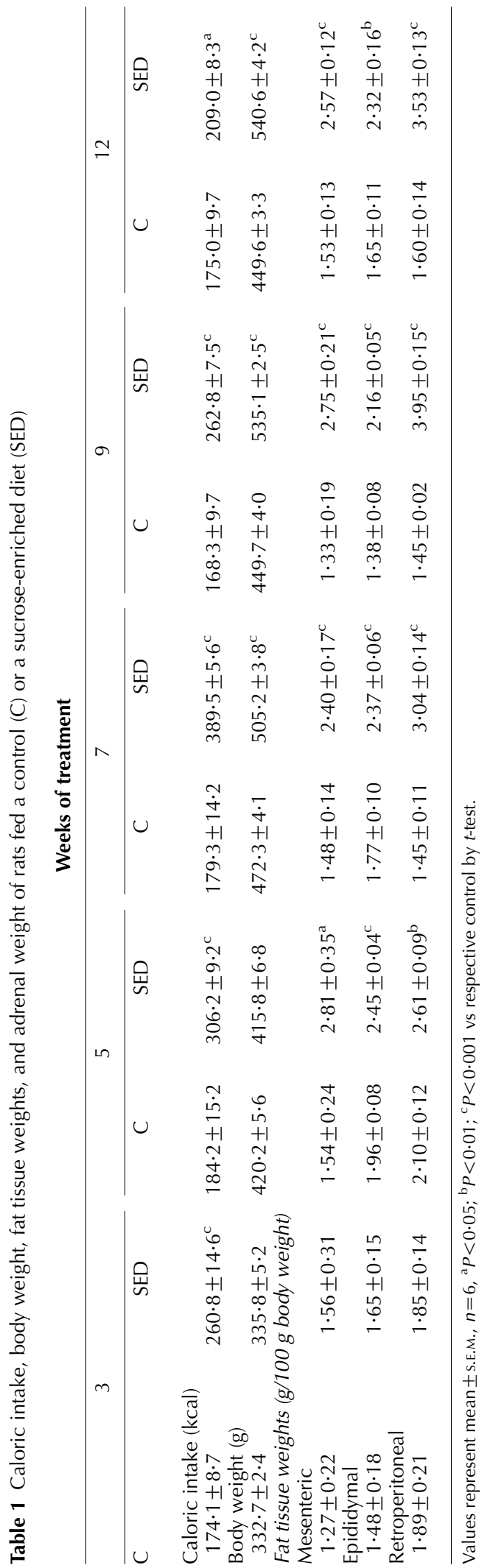

$P<0 \cdot 01, n=9$ /group). Qualitative morphological evaluation (Masson's trichrome stain) of sections obtained from control and SED-treated rats showed, in the latter, disrupted organization of the cords (Fig. 2A and C) and an increased number of markedly vacuolated parenchymatous cells at the zona fasciculata, an effect attributed to the presence of 'lipid ghosts' (Fig. 2E and G, see black arrows). A normal tissue morphology was observed in sections obtained from rosiglitazone-treated control (R) or sucrose-fed animals (SED + R; Fig. 2B, D, F and H).

An evident intracellular infiltration with neutral lipids was observed after staining cryostat adrenal sections, obtained from animals from the SED group, with Sudan III dye (Fig. 3A, C and E). Biochemical analysis indicated a significant accumulation of triglycerides in the adrenocortical tissue (Fig. 3F). Rosiglitazone treatment significantly decreased the lipid infiltration of the adrenal cortex observed in the SED group $(\mathrm{SED}+\mathrm{R})$ as it induced a reduction in the lipid droplets area (as reflected in the diminished Sudan IIIpositive staining in the zona fasciculata layer) and in the triglyceride content of the tissue (Fig. 3A, B, C, D, E and F).

A significant increase in the mRNA levels of Ppar $\gamma$ and its downstream target CD36 (FAT) were detected in the adrenal cortex of SED-treated rats. Rats receiving rosiglitazone also showed an increase in the expression levels of $\mathrm{Cd} 36$ but not in Ppary (Fig. 4). The expression levels of cyclin E and $\mathrm{D}$ were not affected by these treatments (data not shown).

Rats fed a SED displayed significantly higher basal corticosterone levels (Fig. 5A). Nonetheless, a blunted secretory response to i.v. ACTH was detected in these animals (Fig. 5B and inset showing the AUC). Compared with their control counterparts, increased expression levels of Star and Cyp11A1, and a significant decrease in the expression levels of the $\mathrm{ACTH}$ receptor $\mathrm{Mc} 2 \mathrm{r}$, were observed in the adrenal cortex of animals in the SED group (Fig. 5C).

Rosiglitazone treatment prevented the increase in basal corticosterone levels and the reduction in the adrenal response to an acute ACTH stimulation (Fig. 5A and B). The expression levels of adrenocortical Star, Cyp11A1, and $M c 2 r$ were normalized by rosiglitazone (Fig. 5C). Rosiglitazone, per se, induced a significant increase in basal and ACTH-stimulated corticosterone production and in the expression levels of Star, Cyp11A1, and $M c 2 r$ (Fig. 5A, $\mathrm{B}, \mathrm{C}$ and D).

\section{Discussion}

According to our results, morphological changes arise in the adrenal cortex of male adult Wistar rats during the induction of IR by means of a SED. Furthermore, sucrose-treated animals display a concurrent dysregulation of basal and ACTH-stimulated glucocorticoid release.

Several studies have demonstrated that SEDs have a profound impact on fuel accumulation and distribution in rats. 


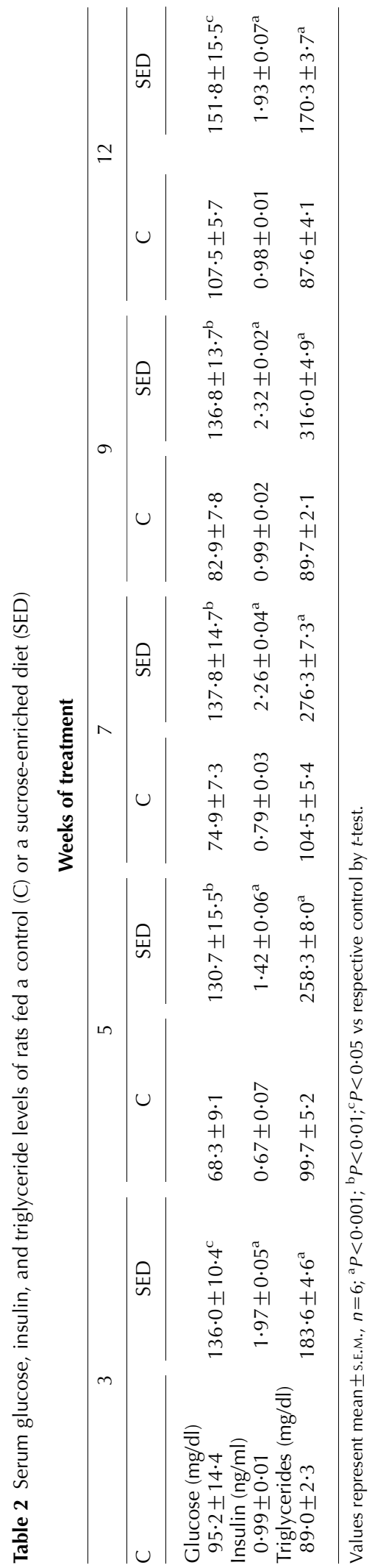

Fructose generated by sucrose hydrolysis in the gut is mainly metabolized in the liver. As it bypasses key regulatory steps in glycolysis, most of the fructose ingested is promptly converted to fatty acids that are esterified into triglycerides, which are then packed into lipoproteins along with cholesterol for blood transport. In agreement, increased fructose intake has been demonstrated to augment serum triglyceride and non-HDL cholesterol levels in humans and rodents (Parks \& Hellerstein 2000, Ryu \& Cha 2003). Similar results were obtained in our experimental conditions when we fed rats 30\% sucrose in the drinking water.

In addition, it was previously shown that high sucrose feeding results in an early development of IR (Bernal et al. 1995) and that this IR state is related to a dysregulation in the production and/or metabolism of glucocorticoids (Bjorntorp \& Rosmond 1999, Walker 2006). Taking this into account, we decided to study adrenal morphology and function during the seventh week of treatment, as, according to our time course studies, IR was frankly established in rats fed the high-sucrose diet at this time point.

Rosiglitazone is a thiazolidinedione (TZD) that serves as a high-affinity ligand of PPAR $\gamma$, a member of the nuclear receptor superfamily of transcription factors (Lehmann et al. 1995). In humans, as well as in animal models, activation of the PPAR $\gamma$ pathway results in the attenuation of IR associated with obesity, impaired glucose tolerance, type 2 diabetes, hypertension, and polycystic ovary syndrome (Potenza et al. 2006, Radosh 2009). Present experiments show that, in SED-treated rats, rosiglitazone administration had no effect on body weight gain or on the adipose tissue depot size. However, as described in other animal models (Jiang et al. 2002, Sharabi et al. 2007), serum glucose, insulin, and triglyceride levels were lowered by concurrent rosiglitazone treatment, suggesting an amelioration of the insulin-resistant state induced by high sucrose feeding. In fact, a normal response to the ITT was achieved when rats were simultaneously treated with rosiglitazone and SED.

Histological examination of adrenocortical sections obtained from SED-treated animals showed a considerable triglyceride infiltration and a disruption of the trabecular organization of the zona fasciculata, without evident effects on the thickness of this layer. Animals rendered insulin resistant by means of SEDs show a considerable increase in hepatic triglyceride synthesis and augmented body fat storage, resulting in abdominal adipose tissue accumulation, and in ectopic fat deposits such as those well described in liver (nonalcoholic steatosis) and muscle (Chicco et al. 2003, Lara-Castro \& Garvey 2008). As in other tissues, in the adrenal cortex, triglyceride synthesis from blood-borne fatty acids could entail the protection from the deleterious effects exerted by free fatty acids or by other metabolites such as diacylglycerol, ceramides, etc. (Listenberger et al. 2003, Consitt et al. 2009). To our knowledge, this is the first report showing the ectopic accumulation of lipids in the adrenal cortex of rats fed a high-sucrose diet. The contribution of steroidogenic cells, macrophages, and/or 

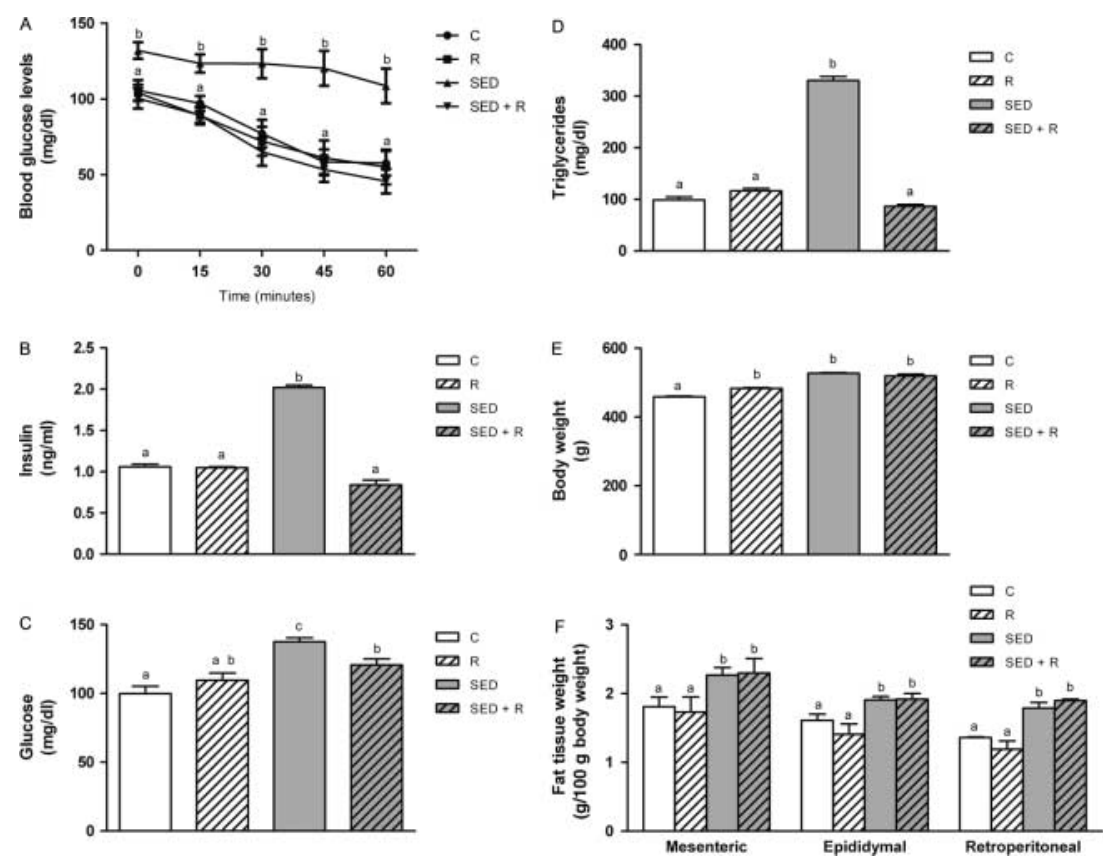

Figure 1 ITT, serum insulin, glucose, and triglyceride levels and body and fat tissue weights in rats fed a SED simultaneously treated with or without rosiglitazone $(\mathrm{R})$. Animals were fed a control diet or a sucrose-enriched diet (C and SED groups) with or without co-treatment with rosiglitazone (4 mg/kg p.o.; $\mathrm{R}$ and $\mathrm{SED}+\mathrm{R}$ groups) as described in the Materials and Methods section for 7 weeks. (A) An ITT was performed after a 6-h fast by i.p. administration of regular porcine insulin $(0.75 \mathrm{IU} / \mathrm{kg})$, (B) serum insulin levels were determined with a commercial ELISA kit. Serum glucose (C) and triglyceride (D) levels were determined by an enzymatic colorimetric commercial kit. Body and fat tissue weights are indicated in (E and F) respectively. Data are expressed as mean \pm S.E.M., $n=6$. Means with different letters are significantly different (Tukey's test, $P<0 \cdot 05$ ).

adipose cells to these ectopic lipid depots within the adrenal cortex is still under investigation.

According to our results, rosiglitazone treatment of highsucrose-fed rats was accompanied by a significant reduction of adrenocortical lipid infiltration. This could arise as a consequence of a well-known effect of TZDs, increasing adipocyte replication and free fatty acid uptake into these cells, and thereby reducing the amount of ectopically deposited fat (Oakes et al. 2001, Yki-Jarvinen 2004). Beyond the reversal of metabolic and low-grade inflammatory
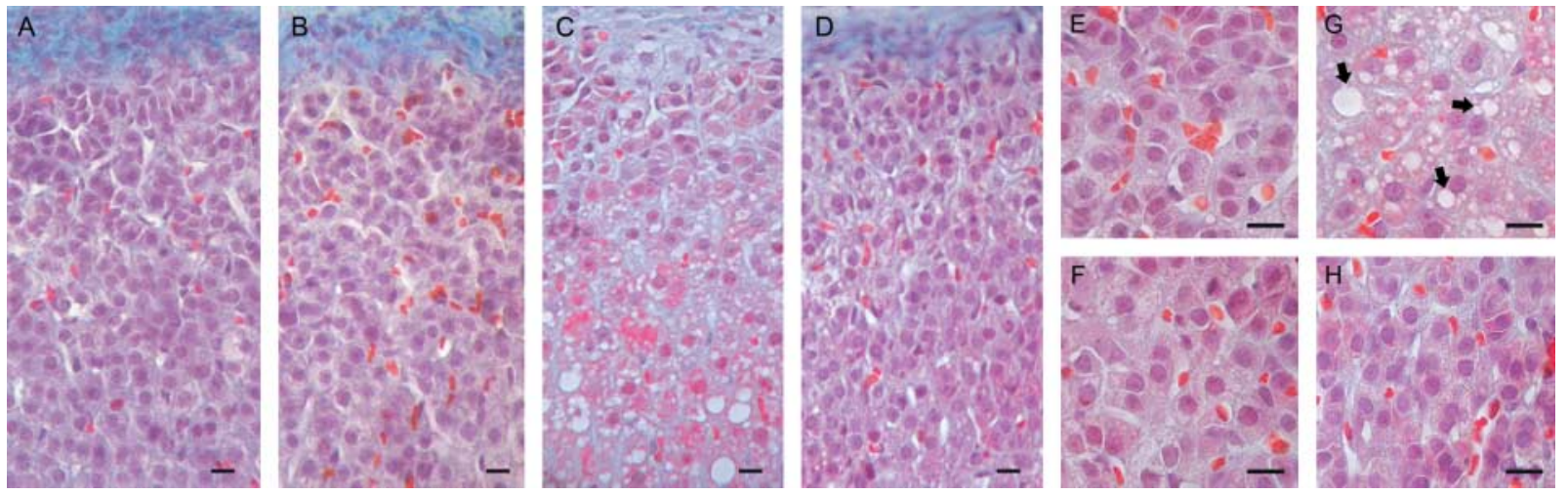

Figure 2 Morphological changes in the adrenal zona fasciculata sections from rats fed a SED with or without rosiglitazone co-treatment (R). Animals were killed and adrenal glands from control (panels A and E), rosiglitazone-treated (panels B and F), SED-treated (panels C and $\mathrm{G}$ ), and SED + R-treated (panels D and H) animals were excised. Paraffin sections of adrenal tissues were stained with Masson's trichrome stain as described in the Materials and Methods section. Black arrows, in (G), show lipid ghosts left by the lipid droplet as a result of staining procedures. Scale bar: A, B, C and $D=10 \mu \mathrm{m} ; \mathrm{E}, \mathrm{F}, \mathrm{G}$ and $\mathrm{H}=5 \mu \mathrm{m}$. 

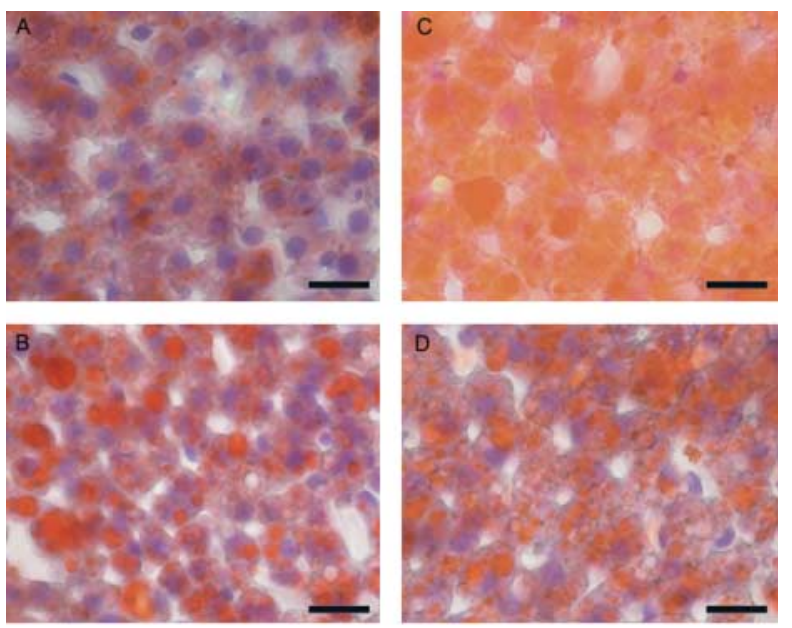

E

$\mathrm{F}$
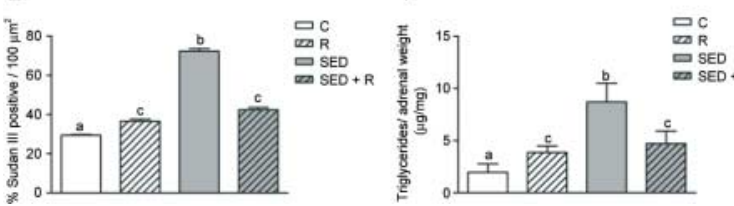

Figure 3 Lipid accumulation on adrenal cortex in rats fed a SED co-treated with or without rosiglitazone (R). Cryostat sections of the adrenal cortex were stained with Sudan III. Images from control (A), $R(B), S E D(C)$, and SED + R (D) animals are shown. Scale bar: A, B, $\mathrm{C}$ and $\mathrm{D}=10 \mu \mathrm{m}$. (E) Histological analysis is indicated as percentage of Sudan III-positive staining per $1000 \mu \mathrm{m}^{2}$.

(F) Triglyceride content of the adrenal tissue is expressed as microgram triglycerides per milligram adrenal weight. Data are expressed as mean \pm S.E.M. $(n=9)$. Means with different letters are significantly different (Tukey's test, $P<0 \cdot 05$ ).

parameters characteristic of the insulin-resistant state, rosiglitazone could possibly exert direct effects at the adrenal level. In this sense, our results showed that both control and SED-treated rats expressed Ppar $\gamma$ in the adrenal cortex. In agreement, the expression of PPAR $\gamma$ in the normal human adrenal cortex (Uruno et al. 2011), in human adrenocortical tumors, and in the adrenocortical cell line H295R was also demonstrated (Betz et al. 2005). Noteworthy, significantly higher levels of PPAR $\gamma$ were determined in the adrenal cortex of rats fed a SED diet. This receptor appears to be functional as a downstream target, CD36 (or FAT), and is also significantly increased in this tissue. Fatty acids and derivatives or other metabolites could be acting as endogenous ligands for PPAR $\gamma$ in the adrenal cortex of SED-treated rats (Ruan et al. 2008). It could then be hypothesized that activation of PPAR $\gamma$ within the adrenal cortex, in the context of the IR state, could result in the upregulation of adipogenic genes, contributing to the lipid deposition observed in the adrenocortical tissue. On the other hand, a reduction in blood triglyceride levels by systemic rosiglitazone treatment of sucrose-fed animals could result in the lower lipid accumulation observed within the adrenal cortex of SED + R-treated animals. Notwithstanding, in this condition, higher adrenal lipid depots were detected, compared with controls, possibly by rosiglitazone-dependent activation of adrenal PPAR $\gamma$.

SED-treated rats showed a significant increase in basal serum corticosterone levels (measured during the morning hours). As stated before, this abnormality has been previously observed both in genetic and in diet-induced animal models of IR: in particular, high-fat diets correlate with higher corticosterone levels in rats (Cano et al. 2008, Buchenauer et al. 2009). This could result from an altered corticosterone metabolism or uptake by peripheral tissues (Kotelevtsev et al. 1997, Masuzaki et al. 2001, Masuzaki \& Flier 2003, Paterson et al. 2004) or from the stimulation of the HPA axis resulting in a higher ACTH output, as described in subjects with IR/central obesity (Jessop et al. 2001, Grayson et al. 2010). Increased expression of STAR and CYP11A1, two key proteins involved in the early steps of steroidogenesis, suggests that augmented glucocorticoid synthesis is responsible, at least in part, for the higher basal corticosterone levels (Miller 1995, Strauss et al. 1999, Manna et al. 2009). The possible contribution of ACTH and/or other still unidentified molecules in this increase is currently under investigation. However, the fact that adrenal weights and the expression levels of the ACTH receptor (MC2R) were significantly lower in the SED-treated group prompt us to propose the involvement of effectors, other than ACTH, in the genesis of basal hypercorticosteronemia.

Among the possible effectors of adrenal steroidogenesis, increased levels of fatty acids or other lipid metabolites, within the adrenal cortex, could be involved in the dysregulation of basal corticosterone production (Sarel \& Widmaier 1995, Rabano et al. 2003). In addition, the regulation of steroidogenesis by adipocyte secretory products generated by fat cells detected in close contact with steroidogenic cells has also been shown (Ehrhart-Bornstein et al. 2003).

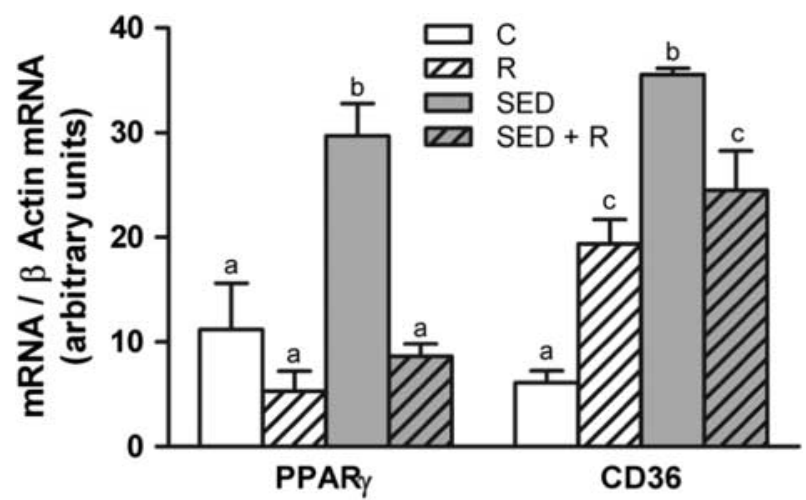

Figure 4 Ppar $\gamma$ and Cd36 mRNA levels in rats fed a SED with or without rosiglitazone treatment $(R)$. Animals were treated as described in the legend of Fig. 1. Adrenal glands from $C, R, S E D$, and SED $+R$ groups were excised and mRNA levels of Ppar $\gamma$ and $\mathrm{Cd} 36$ were determined as described in the Materials and Methods section. Data are expressed as mean \pm S.E.M. $(n=9)$. Means with different letters are significantly different (Tukey's test, $P<0 \cdot 05)$. 

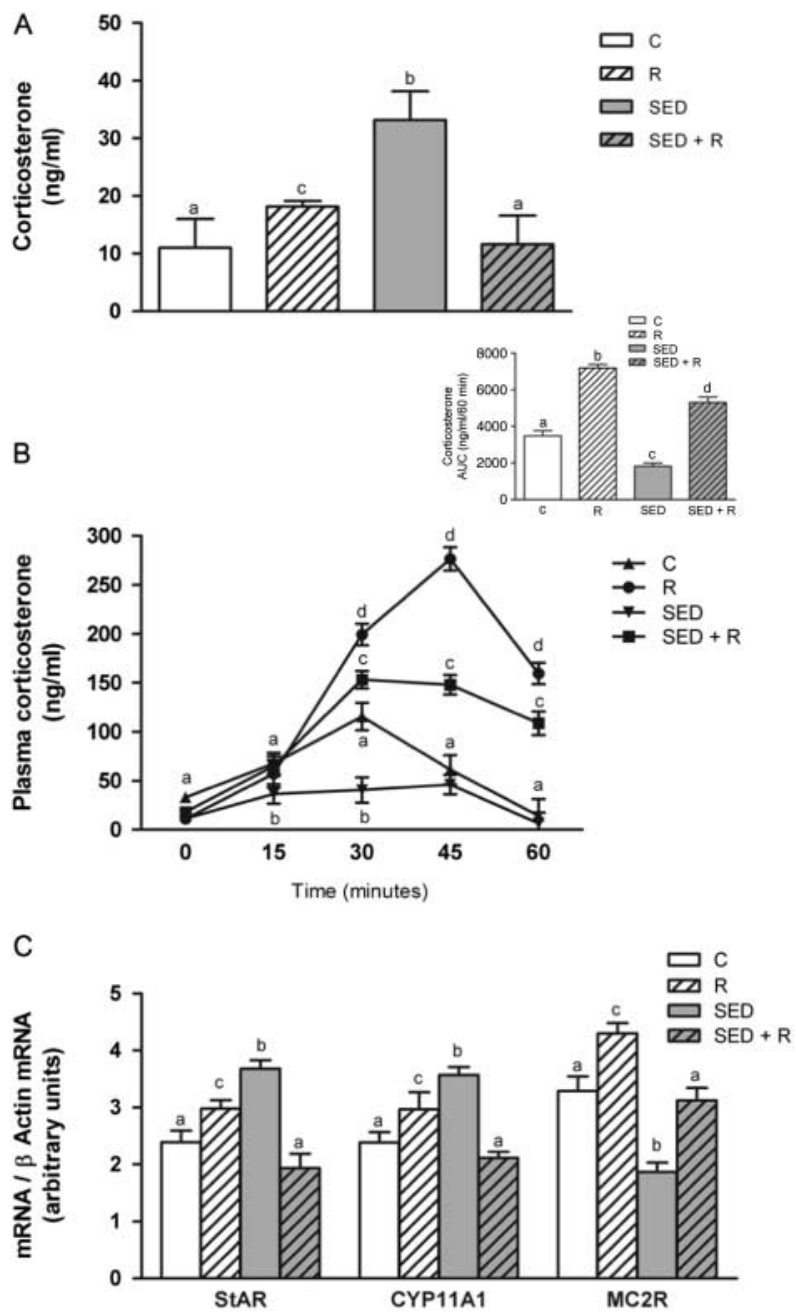

Figure 5 Steroidogenic function in rats fed a SED with or without rosiglitazone treatment $(R)$. Animals were randomly assigned to four experimental groups as described in the legend of Fig. 1 (C, R, SED, and SED $+R$ ), and the following determinations were performed 7 weeks after the initiation of the dietary modification. (A) Basal serum corticosterone levels were determined by RIA, (B) animals were injected with ACTH (4 IU/kg i.v.) and blood was obtained after $0,15,30,45$, and $60 \mathrm{~min}$. Serum corticosterone levels at each time point were determined by RIA. The area under the curve is shown as an inset (AUC, 0-60 min). (C) Adrenal glands from C, R, SED, and $\mathrm{SED}+\mathrm{R}$ groups were excised and mRNA levels of Star and Cyp11A1 were determined as described in the Materials and Methods section. A real-time PCR analysis of the mRNA levels of Star, Cyp11A1, and Mc2r was performed. Data are expressed as mean \pm S.E.M. $(n=9)$. Means with different letters are significantly different (Tukey's test, $P<0 \cdot 05)$.

The effect of circulating adipokines/cytokines (Michl et al. 2000, Bornstein et al. 2004, Mikhaylova et al. 2007) and even of cytokines originated within the adrenal tissue must also be taken into account (Engstrom et al. 2008). In particular, preliminary results from our laboratory indicate a macrophage infiltration of the adrenal cortex and increased expression levels of tumor necrosis factor $\alpha(\mathrm{TNF} \alpha)$ and interleukin $1 \beta$ during the first weeks of treatment (data not shown).

On the other hand, lower adiponectin levels, as those present in the insulin-resistant state (Kadowaki et al. 2006), could contribute to the increased basal corticosterone secretion and augmented Star and Cyp11A1 expression observed in our animal model, as adiponectin inhibits basal and ACTH-stimulated steroid secretion affecting the expression of several steroidogenic genes in adrenal cells ( $\mathrm{Li}$ et al. 2009). Furthermore, Paschke et al. (2010) described an inhibitory effect of adiponectin on basal corticosterone output by freshly isolated rat adrenocortical cells.

As basal corticosterone levels are significantly increased in SED-treated animals, the finding of a blunted response to acute ACTH stimulation may be considered as somewhat confusing. This apparent contradiction can be explained by the fact that sucrose-treated animals display significantly lower Mc2r expression levels in the adrenal cortex (l'Allemand et al. 1996, Lichtenauer et al. 2007, Waddell et al. 2010). The origin and significance of this finding deserve further investigation.

As regards adrenal function, rosiglitazone treatment restored basal corticosteronemia to normal and prevented the increase in Star and Cyp11A1 mRNA levels observed in the SED group, an effect that can be attributed to a decrease in adrenocortical free fatty acid levels and/or lipid deposition. TZDs, on the other hand, have been shown to modify circulating levels of different adipocytokines (e.g. increasing adiponectin and lowering TNF $\alpha$ concentrations) in insulinresistant subjects and experimental animals, exerting beneficial effects on glycemic control, insulin sensitivity, and insulin secretion (Miyazaki \& DeFronzo 2008). Changes in one or more of these cytokines could account for the observed effects on corticosterone levels in SED-treated animals receiving rosiglitazone.

As for the effects of rosiglitazone alone on adrenal steroidogenesis, our results show an increase in basal and ACTH-dependent steroid production with higher levels of Star, Cyp11A1, and Mc2r mRNA levels. It could be hypothesized that these results could be a consequence of a direct effect of rosiglitazone at the adrenal level, as incubation of human adrenal H295R cells with rosiglitazone resulted in higher basal and ACTH-stimulated cortisol production with an increase in Star and $M c 2 r$ (but not in Cyp11A1) mRNA expression levels (Betz et al. 2005). It is clear that additional regulatory pathways (besides PPAR $\gamma$ activation) should be taken into consideration to explain, for instance, the decrease in adrenal $M c 2 r$ expression levels observed in SED-treated animals. On the other side, rosiglitazone treatment does not appear to affect normal adrenal cell proliferation rates as it did not modify the levels of cyclin D and E, two regulators of the cell cycle.

In summary, SED-associated IR might affect adrenocortical cells by inducing lipid infiltration. Without disregarding possible effects exerted at higher levels of the HPA axis and/or on steroid metabolism, the observed changes in 
steroid production could be attributed to direct effects on locally produced adipokines, immune system mediators, and/or lipid metabolites. These changes were prevented by the administration of a PPAR $\gamma$ agonist, acting by means of previously described effects (diminished IR and lipid infiltration and reduced systemic inflammation), and/or through other mechanisms exerted directly at the adrenal level.

\section{Declaration of interest}

The authors declare that there is no conflict of interest that could be perceived as prejudicing the impartiality of the research reported.

\section{Funding}

This work was supported by grants from Agencia Nacional de Promoción de Ciencia y Tecnología (ANPCyT, PICT 2008 N $^{\circ}$ 1034) and from Universidad de Buenos Aires (UBACyT M014).

\section{Acknowledgements}

The authors wish to thank Dr Valeria Rettori for critical reading of the manuscript.

\section{References}

Bernal CA, Gutman RA \& Lombardo YB 1995 The duration of feeding on a sucrose-rich diet determines variable in vitro effects of insulin and fructose on rat liver triglyceride metabolism. Journal of Nutritional Biochemistry 6 422-430. (doi:10.1016/0955-2863(95)00065-8)

Betz MJ, Shapiro I, Fassnacht M, Hahner S, Reincke M \& Beuschlein F 2005 Peroxisome proliferator-activated receptor- $\gamma$ agonists suppress adrenocortical tumor cell proliferation and induce differentiation. Journal of Clinical Endocrinology and Metabolism 90 3886-3896. (doi:10.1210/jc.2004-1267)

Bjorntorp P \& Rosmond R 1999 Visceral obesity and diabetes. Drugs 58 (Suppl 1) 13-18 (discussion 75-82). (doi:10.2165/00003495-19995800100005)

Bornstein SR, Rutkowski H \& Vrezas I 2004 Cytokines and steroidogenesis. Molecular and Cellular Endocrinology 215 135-141. (doi:10.1016/j.mce.2003. 11.022)

Bray GA, Nielsen SJ \& Popkin BM 2004 Consumption of high-fructose corn syrup in beverages may play a role in the epidemic of obesity. American Journal of Clinical Nutrition 79 537-543.

Buchenauer T, Behrendt P, Bode FJ, Horn R, Brabant G, Stephan M \& Nave H 2009 Diet-induced obesity alters behavior as well as serum levels of corticosterone in F344 rats. Physiology \& Behavior 98 563-569. (doi:10.1016/j.physbeh.2009.09.003)

Bugger H \& Abel ED 2008 Molecular mechanisms for myocardial mitochondrial dysfunction in the metabolic syndrome. Clinical Science $\mathbf{1 1 4}$ 195-210. (doi:10.1042/CS20070166)

Cano P, Jimenez-Ortega V, Larrad A, Reyes Toso CF, Cardinali DP \& Esquifino AI 2008 Effect of a high-fat diet on 24-h pattern of circulating levels of prolactin, luteinizing hormone, testosterone, corticosterone, thyroid-stimulating hormone and glucose, and pineal melatonin content, in rats. Endocrine 33 118-125. (doi:10.1007/s12020-008-9066-x)

Chicco A, D'Alessandro ME, Karabatas L, Pastorale C, Basabe JC \& Lombardo YB 2003 Muscle lipid metabolism and insulin secretion are altered in insulin-resistant rats fed a high sucrose diet. Journal of Nutrition $\mathbf{1 3 3}$ $127-133$
Consitt LA, Bell JA \& Houmard JA 2009 Intramuscular lipid metabolism, insulin action, and obesity. IUBMB Life 61 47-55. (doi:10.1002/iub.142)

Cymeryng CB, Dada LA \& Podesta EJ 1998 Effect of nitric oxide on rat adrenal zona fasciculata steroidogenesis. Journal of Endocrinology $\mathbf{1 5 8}$ 197-203. (doi:10.1677/joe.0.1580197)

Dallman MF, la Fleur SE, Pecoraro NC, Gomez F, Houshyar H \& Akana SF 2004 Minireview: glucocorticoids - food intake, abdominal obesity, and wealthy nations in 2004. Endocrinology 145 2633-2638. (doi:10.1210/en. 2004-0037)

Ehrhart-Bornstein M, Lamounier-Zepter V, Schraven A, Langenbach J, Willenberg HS, Barthel A, Hauner H, McCann SM, Scherbaum WA \& Bornstein SR 2003 Human adipocytes secrete mineralocorticoid-releasing factors. PNAS 100 14211-14216. (doi:10.1073/pnas.2336140100)

Engstrom L, Rosen K, Angel A, Fyrberg A, Mackerlova L, Konsman JP, Engblom D \& Blomqvist A 2008 Systemic immune challenge activates an intrinsically regulated local inflammatory circuit in the adrenal gland. Endocrinology 149 1436-1450. (doi:10.1210/en.2007-1456)

Grayson BE, Levasseur PR, Williams SM, Smith MS, Marks DL \& Grove KL 2010 Changes in melanocortin expression and inflammatory pathways in fetal offspring of nonhuman primates fed a high-fat diet. Endocrinology 151 1622-1632. (doi:10.1210/en.2009-1019)

Harms PG \& Ojeda SR 1974 A rapid and simple procedure for chronic cannulation of the rat jugular vein. Journal of Applied Physiology 36 391-392.

Jessop DS, Dallman MF, Fleming D \& Lightman SL 2001 Resistance to glucocorticoid feedback in obesity. Journal of Clinical Endocrinology and Metabolism 86 4109-4114. (doi:10.1210/jc.86.9.4109)

Jiang G, Dallas-Yang Q, Li Z, Szalkowski D, Liu F, Shen X, Wu M, Zhou G, Doebber T, Berger J et al. 2002 Potentiation of insulin signaling in tissues of Zucker obese rats after acute and long-term treatment with PPAR $\gamma$ agonists. Diabetes 51 2412-2419. (doi:10.2337/diabetes.51.8.2412)

Kadowaki T, Yamauchi T, Kubota N, Hara K, Ueki K \& Tobe K 2006 Adiponectin and adiponectin receptors in insulin resistance, diabetes, and the metabolic syndrome. Journal of Clinical Investigation 116 1784-1792. (doi:10.1172/JCI29126)

Kaplan NM 1989 The deadly quartet. Upper-body obesity, glucose intolerance, hypertriglyceridemia, and hypertension. Archives of Internal Medicine 149 1514-1520. (doi:10.1001/archinte.1989.00390070054005)

Kotelevtsev Y, Holmes MC, Burchell A, Houston PM, Schmoll D, Jamieson P, Best R, Brown R, Edwards CR, Seckl JR et al. 1997 11ß-Hydroxysteroid dehydrogenase type 1 knockout mice show attenuated glucocorticoidinducible responses and resist hyperglycemia on obesity or stress. PNAS 94 14924-14929. (doi:10.1073/pnas.94.26.14924)

Krebs M \& Roden M 2004 Nutrient-induced insulin resistance in human skeletal muscle. Current Medicinal Chemistry 11 901-908. (doi:10.2174/ 0929867043455620)

l'Allemand D, Penhoat A, Lebrethon MC, Ardevol R, Baehr V, Oelkers W \& Saez JM 1996 Insulin-like growth factors enhance steroidogenic enzyme and corticotropin receptor messenger ribonucleic acid levels and corticotropin steroidogenic responsiveness in cultured human adrenocortical cells. Journal of Clinical Endocrinology and Metabolism 81 3892-3897. (doi:10.1210/jc.81.11.3892)

Lara-Castro C \& Garvey WT 2008 Intracellular lipid accumulation in liver and muscle and the insulin resistance syndrome. Endocrinology and Metabolism Clinics of North America 37 841-856. (doi:10.1016/j.ecl. 2008.09.002)

Lehmann JM, Moore LB, Smith-Oliver TA, Wilkison WO, Willson TM \& Kliewer SA 1995 An antidiabetic thiazolidinedione is a high affinity ligand for peroxisome proliferator-activated receptor $\gamma(\operatorname{PPAR} \gamma)$. Journal of Biological Chemistry 270 12953-12956. (doi:10.1074/jbc.270.50.30221)

Li P, Sun F, Cao HM, Ma QY, Pan CM, Ma JH, Zhang XN, Jiang H, Song HD \& Chen MD 2009 Expression of adiponectin receptors in mouse adrenal glands and the adrenocortical Y-1 cell line: adiponectin regulates steroidogenesis. Biochemical and Biophysical Research Communications 390 1208-1213. (doi:10.1016/j.bbrc.2009.10.122)

Lichtenauer UD, Duchniewicz M, Kolanczyk M, Hoeflich A, Hahner S, Else T, Bicknell AB, Zemojtel T, Stallings NR, Schulte DM et al. 2007 
Pre-B-cell transcription factor 1 and steroidogenic factor 1 synergistically regulate adrenocortical growth and steroidogenesis. Endocrinology 148 693-704. (doi:10.1210/en.2006-0681)

Listenberger LL, Han X, Lewis SE, Cases S, Farese RV Jr, Ory DS \& Schaffer JE 2003 Triglyceride accumulation protects against fatty acid-induced lipotoxicity. PNAS 100 3077-3082. (doi:10.1073/pnas.0630588100)

Manna PR, Dyson MT \& Stocco DM 2009 Regulation of the steroidogenic acute regulatory protein gene expression: present and future perspectives. Molecular Human Reproduction 15 321-333. (doi:10.1093/molehr/gap025)

Masuzaki H \& Flier JS 2003 Tissue-specific glucocorticoid reactivating enzyme, $11 \beta$-hydroxysteroid dehydrogenase type 1 (11 $\beta$-HSD1) - a promising drug target for the treatment of metabolic syndrome. Current Drug Targets. Immune, Endocrine and Metabolic Disorders 3 255-262. (doi:10.2174/1568008033340135)

Masuzaki H, Paterson J, Shinyama H, Morton NM, Mullins JJ, Seckl JR \& Flier JS 2001 A transgenic model of visceral obesity and the metabolic syndrome. Science 294 2166-2170. (doi:10.1126/science.1066285)

Michl P, Beikler T, Engelhardt D \& Weber MM 2000 Interleukin-3 and interleukin-6 stimulate bovine adrenal cortisol secretion through different pathways. Journal of Neuroendocrinology 12 23-28. (doi:10.1046/j.13652826.2000.00423.x)

Mikhaylova IV, Kuulasmaa T, Jaaskelainen J \& Voutilainen R 2007 Tumor necrosis factor- $\alpha$ regulates steroidogenesis, apoptosis, and cell viability in the human adrenocortical cell line NCI-H295R. Endocrinology 148 386-392. (doi:10.1210/en.2006-0726)

Miller WL 1995 Mitochondrial specificity of the early steps in steroidogenesis. Journal of Steroid Biochemistry and Molecular Biology 55 607-616. (doi:10.1016/0960-0760(95)00212-X)

Miyazaki Y \& DeFronzo RA 2008 Rosiglitazone and pioglitazone similarly improve insulin sensitivity and secretion, glucose tolerance and adipocytokines in type 2 diabetic patients. Diabetes, Obesity \& Metabolism 10 1204-1211.

Oakes ND, Thalen PG, Jacinto SM \& Ljung B 2001 Thiazolidinediones increase plasma-adipose tissue FFA exchange capacity and enhance insulin-mediated control of systemic FFA availability. Diabetes $\mathbf{5 0}$ 1158-1165. (doi:10.2337/diabetes.50.5.1158)

Parks EJ \& Hellerstein MK 2000 Carbohydrate-induced hypertriacylglycerolemia: historical perspective and review of biological mechanisms. American Journal of Clinical Nutrition 71 412-433.

Paschke L, Zemleduch T, Rucinski M, Ziolkowska A, Szyszka M \& Malendowicz LK 2010 Adiponectin and adiponectin receptor system in the rat adrenal gland: ontogenetic and physiologic regulation, and its involvement in regulating adrenocortical growth and steroidogenesis. Peptides 31 1715-1724. (doi:10.1016/j.peptides.2010.06.007)

Pasquali R, Vicennati V, Cacciari M \& Pagotto U 2006 The hypothalamicpituitary-adrenal axis activity in obesity and the metabolic syndrome. Annals of the New York Academy of Sciences 1083 111-128. (doi:10.1196/ annals.1367.009)

Paterson JM, Morton NM, Fievet C, Kenyon CJ, Holmes MC, Staels B, Seckl JR \& Mullins JJ 2004 Metabolic syndrome without obesity: hepatic overexpression of $11 \beta$-hydroxysteroid dehydrogenase type 1 in transgenic mice. PNAS 101 7088-7093. (doi:10.1073/pnas.0305524101)

Potenza MA, Marasciulo FL, Tarquinio M, Quon MJ \& Montagnani M 2006 Treatment of spontaneously hypertensive rats with rosiglitazone and/or enalapril restores balance between vasodilator and vasoconstrictor actions of insulin with simultaneous improvement in hypertension and insulin resistance. Diabetes 55 3594-3603. (doi:10.2337/db06-0667)

Rabano M, Pena A, Brizuela L, Marino A, Macarulla JM, Trueba M \& Gomez-Munoz A 2003 Sphingosine-1-phosphate stimulates cortisol secretion. FEBS Letters 535 101-105. (doi:10.1016/S00145793(02)03882-6)

Radosh L 2009 Drug treatments for polycystic ovary syndrome. American Family Physician 79 671-676.
Reaven GM 1995 Pathophysiology of insulin resistance in human disease. Physiological Reviews 75 473-486.

Ruan X, Zheng F \& Guan Y 2008 PPARs and the kidney in metabolic syndrome. American Journal of Physiology. Renal Physiology 294 F1032-F1047. (doi:10.1152/ajprenal.00152.2007)

Ryu MH \& Cha YS 2003 The effects of a high-fat or high-sucrose diet on serum lipid profiles, hepatic acyl-CoA synthetase, carnitine palmitoyltransferase-I, and the acetyl-CoA carboxylase mRNA levels in rats. Journal of Biochemistry and Molecular Biology 36 312-318. (doi:10.5483/ BMBRep.2003.36.3.312)

Sarel I \& Widmaier EP 1995 Stimulation of steroidogenesis in cultured rat adrenocortical cells by unsaturated fatty acids. American Journal of Physiology 268 R1484-R1490.

Sharabi Y, Oron-Herman M, Kamari Y, Avni I, Peleg E, Shabtay Z, Grossman E \& Shamiss A 2007 Effect of PPAR $-\gamma$ agonist on adiponectin levels in the metabolic syndrome: lessons from the high fructose fed rat model. American Journal of Hypertension 20 206-210. (doi:10.1016/j.amjhyper.2006.08.002)

Shimomura Y, Bray GA \& Lee M 1987 Adrenalectomy and steroid treatment in obese $(o b / o b)$ and diabetic $(d b / d b)$ mice. Hormone and Metabolic Research 19 295-299. (doi:10.1055/s-2007-1011804)

Soria A, D'Alessandro ME \& Lombardo YB 2001 Duration of feeding on a sucrose-rich diet determines metabolic and morphological changes in rat adipocytes. Journal of Applied Physiology 91 2109-2116.

Strauss JF III, Kallen CB, Christenson LK, Watari H, Devoto L, Arakane F, Kiriakidou M \& Sugawara T 1999 The steroidogenic acute regulatory protein (StAR): a window into the complexities of intracellular cholesterol trafficking. Recent Progress in Hormone Research 54 369-394 (discussion 394-395).

Unger RH \& Orci L 2002 Lipoapoptosis: its mechanism and its diseases. Biochimica et Biophysica Acta 1585 202-212. (doi:10.1016/S1388-1981 (02)00342-6)

Uruno A, Matsuda K, Noguchi N, Yoshikawa T, Kudo M, Satoh F, Rainey WE, Hui XG, Akahira J, Nakamura Y et al. 2011 Peroxisome proliferator-activated receptor- $\{\gamma\}$ suppresses CYP11B2 expression and aldosterone production. Journal of Molecular Endocrinology 46 37-49. (doi:10.1677/JME-10-0088)

Voutilainen R 1998 Adrenocortical cells are the site of secretion and action of insulin-like growth factors and TNF- $\alpha$. Hormone and Metabolic Research 30 432-435. (doi:10.1055/s-2007-978910)

Waddell BJ, Bollen M, Wyrwoll CS, Mori TA \& Mark PJ 2010 Developmental programming of adult adrenal structure and steroidogenesis: effects of fetal glucocorticoid excess and postnatal dietary omega- 3 fatty acids. Journal of Endocrinology 205 171-178. (doi:10.1677/JOE-09-0459)

Walker BR 2006 Cortisol - cause and cure for metabolic syndrome? Diabetic Medicine 23 1281-1288. (doi:10.1111/j.1464-5491.2006.01998.x)

Yang R \& Barouch LA 2007 Leptin signaling and obesity: cardiovascular consequences. Circulation Research 101 545-559. (doi:10.1161/CIRCRESAHA.107.156596)

Yki-Jarvinen H 2004 Thiazolidinediones. New England Journal of Medicine 351 1106-1118. (doi:10.1056/NEJMra041001)

Zago V, Lucero D, Macri EV, Cacciagiu L, Gamba CA, Miksztowicz V, Berg G, Wikinski R, Friedman S \& Schreier L 2010 Circulating verylow-density lipoprotein characteristics resulting from fatty liver in an insulin resistance rat model. Annals of Nutrition \& Metabolism 56 198-206. (doi:10.1159/000276596)

Received in final form 9 May 2012

Accepted 13 June 2012

Made available online as an Accepted Preprint 13 June 2012 